\title{
Balkanologie
}

Balkanologie Revue d'études pluridisciplinaires

Vol. IX, n' 1-2 | 2005

Volume IX Numéro 1-2

\section{Dualité orthodoxe au Monténégro}

Dual orthodoxy in Montenegro

\section{Amaël Cattaruzza et Patrick Michels}

\section{(2) OpenEdition}

Journals

Édition électronique

URL : http://journals.openedition.org/balkanologie/595

DOI : 10.4000/balkanologie.595

ISSN : 1965-0582

\section{Éditeur}

Association française d'études sur les Balkans (Afebalk)

Édition imprimée

Date de publication : 1 décembre 2005

ISSN : 1279-7952

\section{Référence électronique}

Amaël Cattaruzza et Patrick Michels, « Dualité orthodoxe au Monténégro », Balkanologie [En ligne], Vol. $\mid X, n^{\circ} 1-2$ | 2005, mis en ligne le 13 janvier 2010, consulté le 17 décembre 2020. URL : http:// journals.openedition.org/balkanologie/595; DOI : https://doi.org/10.4000/balkanologie.595 


\title{
DUALITÉ ORTHODOXE AU MONTÉNÉGRO
}

\author{
Amaël Cattaruzza \& Patrick Michels*
}

La polémique sur la légitimité de l'Église orthodoxe serbe au Monténégro est assez récente : elle apparait au début des années 1990 avec l'affirmation ou la réaffirmation d'une Église orthodoxe autocéphale autoproclamée monténégrine. Cette dualité entre deux Églises orthodoxes au Monténégro accompagne un processus plus général de division identitaire entre des populations se considerant comme serbes et d'autres se revendiquant plus spécifiquement comme monténégrines'. L'autocéphalie de l'Église monténégrine n'est revendiquée par une poignée de Monténégrins que depuis peu et ce mouvement reste encore aujourd'hui minoritaire dans le pays ${ }^{2}$. La première cérémonie pour laquelle a officié l'Église autocéphale du Monténégro eu lieu le 31 octobre 1993. Cette manifestation publique permit l'élection du premier métropolite de l'Église autocéphale monténégrine, Antonije Abramović. Symboliquement, la

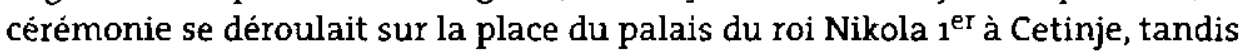

\footnotetext{
- Amaël Cattaruzza est docteur en gèographie (Université de Paris IV), contact : <amaelc@orange.fr〉; Patrick Michels est titulaire d'un DEA de politique comparée (Université de Paris X), contact : 〈patrick.michels@afebalk.org》.

Nous tenons à exprimer nos plus vifs remerciements à Antonela Capelle pour ses conseils et ses commentaires.

${ }^{1}$ Cette division dans la population monténégrine entre une fraction "pro-serbe " et une fraction "promonténégrine " reprend l'ancien clivage entre Verts et Blancs apparu lors des élections parlementaires de 1918 lorsque les partisans d'une union avec la Serbie et d'une intégration au Royaume des Serbes, Croates et Slovènes votaient avec un papier blanc et ceux qui, au contraire, préconisaient l'indépendance et la fidélite à la famille royale des Petrovic Njegoš, votaient avec un papier vert. Aujourd'hui, cette division réapparaît dans un nouveau contexte alors que le Monténégro oscille entre une union renouvelée avec la Serbie et l'indépendance.

2 Il est interessant de constater que, pendant la période communiste, le schisme macédonien de 1967 n'a pas, à l'époque, donné matière à la revendication d'un quelconque séparatisme de l'Église orthodoxe au Monténégro. Selon l'historien Dusan Bataković, des tractations auraient pourtant étaient tentees par les communistes mais en vain, le clergé local s'opposant fortement à cette idée (Bataković (Dušan T.), Yougoslavie. Nations, religions, idéologies, Lausanne : L'Age d'Homme, 1994, p. 246).
} 
que quelques cinquante mètres plus loin, dans le monastère de Cetinje, se tenait la cérémonie officielle de l'Église orthodoxe serbe.

Ce " coup de force " du 31 octobre 1993 dépasse le strict cadre religieux et revêt des aspects identitaires et politiques. Il serait d'ailleurs vraisemblablement passé inaperçu si le contexte sociopolitique n'avait pas participé à renforcer son importance. En effet, l'année 1993 est caractérisée par l'enlisement des conflits yougoslaves en Bosnie-Herzégovine, dans lesquels les Monténégrins participent, enrôlés aux côtés des Serbes dans les rangs de l'Armée yougoslave. La lassitude des combats et de l'encerclement international favorise le développement d'un mouvement pacifiste au Monténégro. Or, au même moment, la presse nationaliste monténégrine souligne le soutien moral apporté par l'Église serbe aux soldats orthodoxes de l'Armée yougoslave. L'apparition, ou la réapparition, d'une Église autocéphale monténégrine se situe donc à la convergence de deux mouvements, l'un national, et l'autre antiguerre, qui peuvent expliquer l'importance que l'évènement prend dans le pays, alors qu'il est au départ confiné à la petite ville de Cetinje. Pourtant, il est largement rapporté dans les médias, salué par les journaux pro-monténégrins et vilipendé par la presse pro-serbe. Le débat public qu'il inaugure sur le choix nécessaire entre une Église serbe ou une Église monténégrine se perpétue jusqu'à aujourd'hui.

La compréhension de ce phénomène, lequel n'est pas seulement conjoncturel et semble s'inscrire dans la durée, puisque les deux Églises continuent aujourd'hui encore à se concurrencer sur le territoire monténégrin, nécessite la prise en compte de plusieurs éléments, à savoir l'ancrage spatial des deux Églises et le dédoublement des lieux de cultes, les fondements historiques qui légitiment l'existence de l'une et de l'autre et les provocations de plus en plus visibles perpétrées des deux côtés.

\section{DÉDOUBLEMENTS DES LIEUX SYMBOLIQUES : DOUBLES CELÉBRATIONS ET CONCURRENCE NATIONALE}

Le lieu symbolique, qu'il soit national, religieux ou d'autre nature, est porteur d'un message communautaire. Il constitue un site fédérateur, un espace de ralliements qui, tout en cristallisant l'idéologie du groupe qui l'a créé, permet à celui-ci de se réunir, de conforter son existence et de perdurer dans le temps. Toutefois, la situation particulière du Monténégro - cette division identitaire entre pro-serbes et pro-monténégrins - a entraîné deux types de processus. D'un côté, on a pu assister à un dédoublement des lieux symboliques nationaux et à la création d'institutions nationales parallèles représentant le nationalisme " pro-monténégrin ". De l'autre, les sites traditionnels religieux 
se sont chargés d'une signification ambiguë suivant les points de vues.

La division de l'Église orthodoxe monténégrine s'inscrit de facto dans ces processus politiques ${ }^{3}$. Ce dédoublement des instances religieuses illustre l'intensité des liens entre le politique et le culturel au Monténégro. Comment comprendre, en effet, l'activation de ces " schismes " institutionnels si ce n'est dans l'espoir d'un renversement possible des hiérarchies et des élites au sein d'un Monténégro indépendant ? Mais, cette concurrence au sein des organes symboliques nationaux entraine une revalorisation d'un certain nombre de lieux symboliques qui se voient appropriés différemment par les "proserbes " et " pro-monténégrins ». Ainsi, le monastère de Cetinje est revendiqué par les deux Églises comme haut lieu culturel. Pour l'Église serbe (Srpska Pravoslavna (rkva - SPC) qui en est propriétaire, il est considéré comme un haut lieu spirituel de la foi orthodoxe serbe d'autant plus symbolique qu'il représente, d'une certaine manière, la permanence de cette foi dans l'histoire. Le Monténégro compte un certain nombre de monastères importants dans la liturgie orthodoxe serbe : le monastère de Cetinje, le monastère Ostrog (incrusté à $671 \mathrm{~m}$ d'altitude sur le flanc d'une montagne près de Nikšić) ou celui de Morača entre Kolašin et Podgorica. Pour l'Église monténégrine (Crnogorska Pravoslavna Crka-CPC), le monastère de Cetinje prend, en plus de sa valeur spirituelle, une dimension nationale. Fondé au cœur du vieux Monténégro4, il incarne l'Église autocéphale de résistance de l'époque ottomane et donc la spécificité monténégrine. À ce titre, l'Église monténégrine réclame encore la restitution du monastère à sa nation.

En revanche, certains lieux sont plus clairement identifiés comme symboles nationaux monténégrins. C'est le cas de la place du palais du roi Nikola ${ }_{1}^{\mathrm{er}}$ à Cetinje 5 , que seuls quelques dizaines de mètres séparent du monastère. Cette place a souvent été utilisée pour les rassemblements populaires pro-monténégrins (célébrations religieuses ou déclarations politiques). La ville de Cetinje, du fait de son histoire et de ce qu'elle représente tant pour les Serbes que pour les Monténégrins, se prête particulièrement à ce type d'analyse visant les différents lieux symboliques et leurs significations nationales à petite échelle. Cette ville apparue au XVème siècle joue un rôle central dans les histoires nationales serbe et monténégrine. Elle devient le centre politique des Monténégrins au temps de l'État médiéval de Zeta, lorsque l'ancienne capitale,

\footnotetext{
${ }^{3}$ De mème, au niveau scientifique, la création en 1999 de la Dukljanska Akademija Nauka i Umjetnosti, l'Académie des Sciences et des Arts de Duklja (du norn du premier État monténégrin), entre également dans cette logique.

4 Le Vieux Monténégro, Stara Crna Gora, reprèsente le foyer originel de lutte des tribus monténégrines contre l'envahisseur attoman. Elle se situe dans la région de Cetinje qui en était la capitale.

5 Le palais, devenu musée, reprèsente une époque où le Monténégro indépendant était reconnu comme acteur autonome sur la scène internationale et jouissait d'une certaine aura diplomatique.
} 
Žabljak, sur le lac de Skadar, est conquise par l'Empire ottoman et qu'Ivan Crnojević, gouverneur du royaume, y installe son palais résidentiel en $1482^{6}$. La place privilégiée de Cetinje dans l'histoire monténégrine depuis plus de six siècles explique l'exceptionnelle concentration de vestiges, de monuments et de bâtiments symboliques (cf. figure 1) pour une agglomération d'importance démographique modeste (18 482 habitants en 2003). Ces lieux d'histoires accumulèes peuvent être classés en plusieurs types suivant le pouvoir qui les a construits, la période qu'ils représentent, leur dimension spirituelle et, plus largement, le message symbolique dont ils sont porteurs.

La ville de Cetinje a, tout d'abord, une importance religieuse. La première église y est construite en 1484 par Ivan Crnojević et ses vestiges sont encore visibles actuellement (monument 9 sur la figure 1). Celle-ci est détruite par les Vénitiens en 1692 mais, quelques mètres plus loin, le vladika gospodar Danilo bâtit, entre 1701 et 1704 , le monastère de Cetinje qu'il dédie à Sainte Marie (monument 5). Bien qu'il ait été endommagé trois fois par des incursions turques au XVIII ${ }^{\text {eme }}$ siècle $(1712,1714$ et 1785$)$, il a toujours été restauré et conservé au cours des siècles. Il fut occupé par les vladike monténégrins qui incarnent alors, pour les populations environnantes, la résistance spirituelle de l'orthodoxie face aux envahisseurs ottomans. Le monastère, aujourd'hui connu sous le nom de " monastère de Saint Pierre de Cetinje " en l'honneur du vladika Pierre ${ }_{1}{ }^{\mathrm{er}}$ qui y repose, abriterait également la main droite de Saint JeanBaptiste. Ce site est revendiqué symboliquement par le camp pro-serbe comme par le camp pro-monténégrin. Du côté serbe, il est le centre de l'archidiocèse du littoral monténégrin de l'Église serbe et, de ce fait, la résidence du métropolite Amfilohije Radović. Du côté montenégrin, il reste la demeure des vladike monténégrins et le centre historique de la tradition orthodoxe montenégrine. Parallèlement, la ville est également parsemée de symboles nationaux monténégrins, souvent hérités des XIXème et XXème siècles. Elle possède notamment les sépultures de tous les vladike et princes de la dynastie des Petrović Njegoś ayant régné jusqu'en $1918^{7}$. Les espaces symboliques parallèles, religieux, nationaux, communistes (cf. figure 1), se cotoient dans la ville et permettent de conforter des nationalismes divergents et contradictoires. Ces processus d'opposition deviennent manifestes lors des célébrations religieuses orthodoxes et de la confrontation des deux Églises.

${ }^{6}$ Cetinje reste alors la capitale politique jusqu'à la disparition du Royaume de Monténégro et son unification au royaume de Serbie en 1918. Le 23 novembre 1946, Podgorica, renommée Titograd, est choisie comme centre politique et administratif. Finalement, le 29 décembre 1993, l'Assemblée monténégrine accorde à la ville le statut de "Prijestonice ", c'est-à-dire de capitale historique et culturelle.

\footnotetext{
7 Parmi les sites les plus reconnus, le mausolée de Petar II trône au sommet du Lovćen qui est devenu un véritable lieu de pèlerinage. La sépulture du vladika Danilo surplombe la ville sur une petite colline au sud (monument 1), la sépulture de Petar I est dans le monastère (monument 5 ), tandis que celles du roi Nikola ${ }^{\text {er }}$ et de son épouse Milena se trouvent dans la petite chapelle construite sur les vestiges de l'église d'Ivan Crnojevic (monument g).
} 


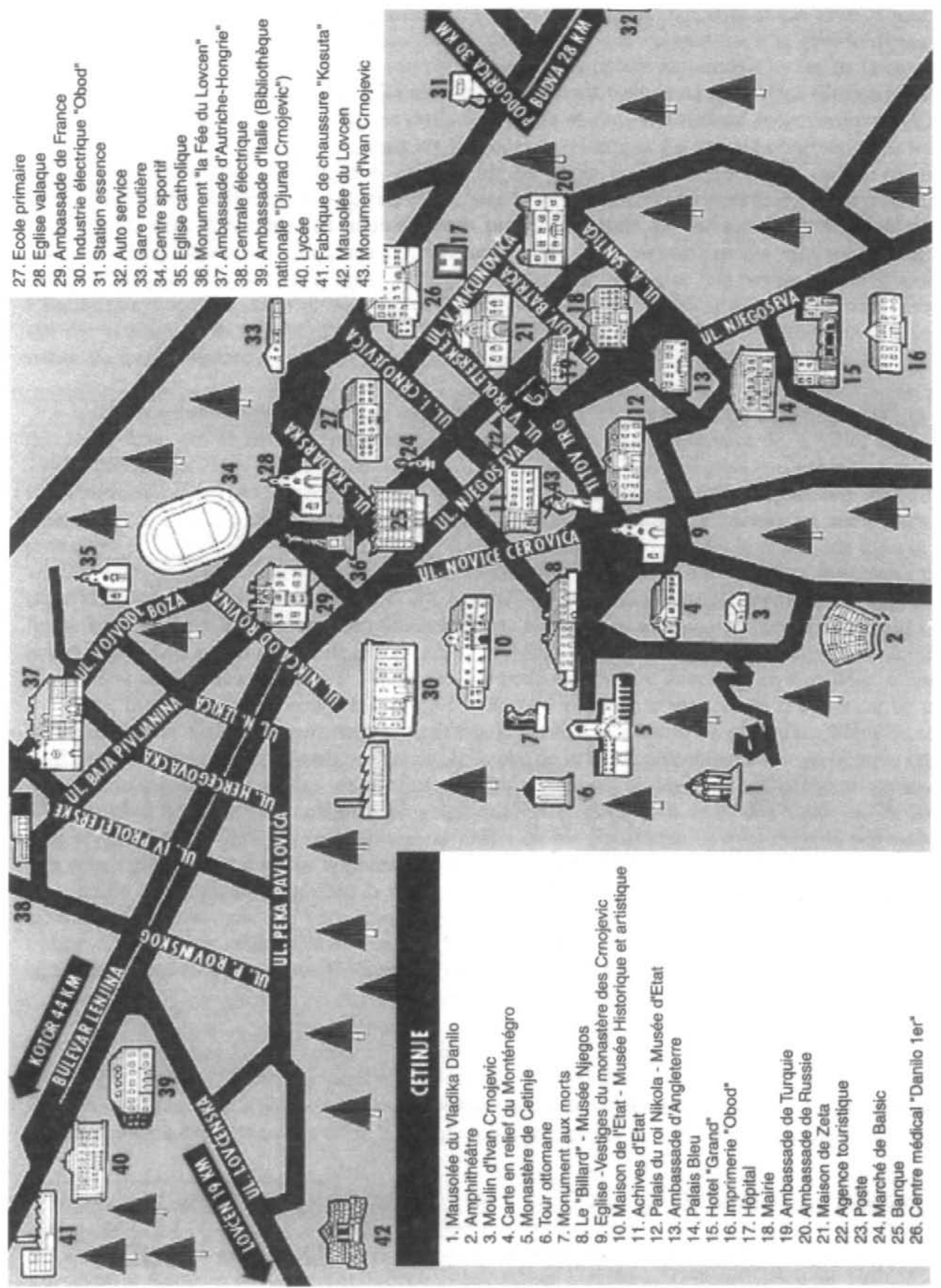

Figure 1 - Identification des lieux et monuments dans le centre de Cetinje 
À Cetinje, les grandes célébrations religieuses orthodoxes se sont dédoublées depuis la création de l'Église orthodoxe autocéphale. Ainsi en est-il de la célébration de Lućindan. Le jour de la Saint-Luc, le 31 octobre, est une slava, c'est-àdire, dans la tradition orthodoxe serbe, la fête d'un saint familial. Ce jour a une signification particulière au Monténégro puisqu'il coïncide avec la liturgie en l'honneur de Sveti Petar Cetinjski (Saint Pierre de Cetinje) qui a appartenu à la grande dynastie des Petrović Njegoš. Cette double célébration prend donc une ampleur nationale. Or, depuis la création de l'Église autocéphale monténégrine, l'évènement est célébré à Cetinje en deux lieux différents : dans le vieux monastère de Cetinje par l'Église orthodoxe serbe et dans une maison reconvertie en église par l'Ėglise autocéphale monténégrine, dans les faubourgs de Cetinje. La liturgie observée dans les deux structures est strictement identique et chacune de ces deux Églises regroupe un certain nombre de fidèles, qui ne se différencient finalement que par leur positionnement politique, la foi orthodoxe se trouvant ici écartelée entre les nationalismes pro-monténégrin et proserbe. Cette division n'est d'ailleurs pas seulement subie mais également créée par les différentes Églises, puisque les protagonistes, à savoir le métropolite de l'Église serbe, Amfilohije, et l'archevêque et métropolite de l'Église monténégrine autocéphale, Mihajlo ${ }^{8}$, interviennent régulièrement sur la question nationale et ont des positions très tranchées, l'un en faveur de l'identité serbe et l'autre valorisant la spécificité nationale monténégrine.

De la même manière, mais de façon plus spectaculaire, la célébration de Badnji dan", le "Jour des Rameaux " qui se déroule traditionnellement devant l'ancien monastère de la ville, s'est depuis 1994, dédoublée. Une célébration parallèle est organisée par l'Église orthodoxe autocéphale monténégrine sur la place du roi Nikola, à une centaine de mètres à peine du monastère, reproduisant fidèlement toute la liturgie, jusqu'à l'embrasement des rameaux. La messe est tenue devant le monastère par le métropolite Amfilohije de l'Église serbe alors que, devant la place, elle est dite par le vladika Mihajlo, patriarche de l'Église monténégrine autoproclamée. Les discours prononcés par les deux autorités religieuses sont teintés d'une coloration nationaliste particulière. Les uns sont souvent liés aux sujets chers à l'Église serbe (attachement au Kosovo, au "srpstvo", ou serbité) tandis que les autres demandent la restitution des monastères du

\footnotetext{
${ }^{8}$ Le mètropolite Mihailo, alias Miraš Dedeić, succède à Antonije Abramović, premier métropolite de l’Église autocéphale montènégrine, décédé à la fin de l'annèe 1996. Monténégrin, il est né le 8 novembre 1938 au village de Ramovo Źdrijelo, près de Savnik. Après avoir étudié la théologie à Prizren et à Belgrade, il termine ses études supérieures à Rome et est invité par le métropolite Filaret à Moscou. Ordonné prêtre en 1988 , il exerça longtemps à l'Église grecque orthodoxe de Rome. Après sa nomination à la tête de l'Église autocéphale monténégrine, il est excommunié de l'Église par le patriarche œcuménique Bartholomé le 9 avril 1997.
}

${ }^{9}$ Badnji dan, le jour des Rameaux, correspond à la célébration de la veille de noël dans la liturgie orthodoxe yougoslave. 
Monténégro à l'Église monténégrine autocéphale. La célébration parallèle de Badnji Dan à Cetinje pourrait sembler anecdotique si celle-ci n'était pas facteur de tension. La police est présente sur les lieux et sépare le monastère de la place par un cordon de sécurité pour veiller au bon déroulement des festivités. Cette double cérémonie signe le clivage entre pro-monténégrin et pro-serbe en créant, le temps de la fête, une concurrence symbolique entre les deux communautés religieuses, se contestant réciproquement la légitimité. Cette confrontation est d'autant plus forte que la proximité géographique est étroite. La plupart des Cetinjani et les pro-monténégrins sont regroupés sur la place du palais du roi Nikola tandis que, du côté pro-serbe, des cars sont affrétés ainsi que des voitures individuelles en provenance de Nikšić, de Podgorica et, d'un peu partout au Monténégro et dans la diaspora, pour venir se recueillir devant le monastère. Chaque camp tente de rassembler un maximum de personnes et le déroulement des deux manifestations fait l'objet d'un compte rendu détaillé dans la presse du lendemain. Cetinje est peu à peu devenue, le temps de Badnji Dan, la vitrine de l'opposition entre les deux Monténégro.

Cette situation pourrait toutefois évoluer puisque ces doubles célébrations tendent actuellement à s'étendre à d'autres villes. En janvier 2003, l'Église autocéphale monténégrine avait ainsi organisé des célébrations parallèles à Podgorica, Nikšić et à Mojkovac. Cette extension de la zone d'influence de l'Église autocéphale monténégrine semblait pouvoir être relativisée, les rassemblements dans les autres villes n'ayant alors concerné qu'une centaine de personnes. Elle s'est toutefois pérennisée depuis et s'est confortée réunissant chaque année dans chacune de ces agglomérations un peu plus de fidèles. Elle doit donc être prise en considération comme un phénomène potentiellement durable.

\section{DEUX ÉGLISES ORTHODOXES EN OUÊTE DE LÉGITIMITÉ}

Chaque partie amene son lot de présomptions dans son affirmation et présente ce qu'elle estime être les racines du problème actuel. Les moyens matériels dont elles disposent ne sont pas les mémes, l'idéologie qu'elles revendiquent est également distincte. Pour l'une, les orthodoxes présents dans l'Union de Serbie-et-Monténégio sont des Serbes qui ne peuvent être rattachés qu'à une seule Église; pour l'autre, les orthodoxes du Monténégro sont des Monténégrins qui devraient dépendre d'une seule Église. Aucune des deux ne remet en cause le caractère national de l'orthodoxie, mais l'Église monténégrine s'affirme non pas en ostracisant mais en affichant son caractère pluriculturel. L'archevêque de l'Église Monténégrine, Mihajlo, insiste sur la différence majeure avec l'Église serbe : il n'y a " pas de baptême dans une église 
serbe si on ne se déclare pas serbe. L'Église monténégrine est une église ouverte. Nous baptiserons tous ceux qui le souhaitent et indiquerons la nationalité qu'ils veulent $n^{10}$. Cette ouverture proclamée est-elle sincère ou participet-elle d'une mise en scène de la part de l'Église monténégrine à des fins de légitimation ? Toujours est-il que l'Église monténégrine a su cultiver une image de tolérance, qui fait souvent défaut à l'Église serbe au Monténégro.

\section{Deux Églises, deux histoires}

Le débat porte sur l'existence historique de l'autocéphalie monténégrine, sa légitimité à représenter les orthodoxes du Monténégro du fait de son "apparition " récente, alors que l'Église serbe, au travers de la Métropolie du Monténégro et du Littoral, est établie depuis longtemps. Historiquement, les Églises orthodoxes ont un caractère national (les Patriarcats de Bulgarie et de Serbie font, par exemple, partie intégrante du processus d'édification étatique et participent activement à l'affirmation de l'identité nationale). Les Églises autocéphales sont créées pour des raisons géopolitiques, étatiques, politiques ou idéologiques. Elles se séparent de l'Église mère de façon non canonique, sans son accord ou contre sa volonté (comme par exemple l'Église Saint Sava du Patriarcat d'Ohrid en 1219) bien que, souvent, l'autocéphalie soit octroyée par un des anciens Patriarcats (Constantinople, parfois Moscou) ${ }^{11}$.

En ce qui concerne l'autocéphalie revendiquée de l'Église orthodoxe monténégrine, pour les défenseurs de la singularité monténégrine, ses racines plongent dans l'histoire : la Dioclée et Raška étaient deux États distincts. D'ailleurs, le premier roi serbe, Stefan Prvovjenčani (1217) ne s'était-il pas proclamé " roi des terres serbes et de la Dioclée ", signifiant par là même que la Dioclée n'est pas une terre serbe ${ }^{12}$ ? En faisant abstraction de cette question,

${ }^{10}$ Dedeić (Miraš), " Put mira i ljubavi " (La voie de la paix et de l'amour), Monitor, 10/01/97.

${ }^{11}$ En plus de la primauté morale des Patriarcats, la tradition orthodoxe reconnait également l'autocéphalie de certaines églises nationales, qui, en retour, acceptent la préséance honorifique du Patriarcat de Constantinople. Cette " autocéphalie " comprend pour l'Église locale la possibilité d'élire son patriarche lors d'un synode patriarcal, ainsi qu'une complète autonomie. Seule restriction, cette élection doit être confirmée par une autre Église autocéphale. Le nouveau patriarche a alors autorité sur les métropolites, les évêques, le clergé et le peuple de son territoire. Cette pratique de l'autocéphalie, introduite en 1448 lorsque l'Église de Moscou se proclame elle-même autocéphale, se généralise au XIXème siècle avec le déclin de l'Empire ottoman et l'émergence de nouvelles nations sur le continent européen. Ainsi, quand la Grèce, la Serbie et la Roumanie accèdent à l'indépendance, le patriarcat de Constantinople reconnaît l'autocéphalie de leur Église.

Pour l'Église bulgare, le processus a été beaucoup plus compliqué. En 1870, un firman du Sultan a confirmé la création d'un Exarchat bulgare. Mais l'État n'étant pas reconnu, l'Église bulgare a été condamnée pour "phylétisme" et exclue des Églises orthodoxes canoniques. Sa réintégration est intervenue uniquement en 1945, donc bien après l'indépendance.

${ }^{12}$ Cf. Radojević (Danilo), " Autokefalna crnogorska pravoslavna crkva kao izraz suvereniteta crnogorske države " (L'Église orthodoxe autocéphale monténégrine comme expression de la souveraineté de l'État monténégrin), in Crna Gora pred izazovima budućnosti (Le Monténégro face au challenge du futur), Cetinje : Matica crnogroska, 1996, p. 221-223. 
nombreux évoquent l'indèpendance de fait de l'Église au Monténégro à l'époque ottomane à partir de 1766 lorsque le Patriarcat de Peć, siège de l'Église orthodoxe serbe, est démantelé13. Mais pour autant, les princes Petrović (princesévêques du Monténégro) n'ont jamais déclaré être commandeurs d'une Église autocéphale ${ }^{14}$. Ce n'est qu'après le Congrès de Berlin en 1878 que le Patriarcat de Constantinople (Istanbul) confère l'autocéphalie aux Églises de Serbie et de Karlovac (autonomes depuis 1831) 15. L'Église du Monténégro n'est pas concernée.

L'histoire étant sujette à interprétations, il est fait appel à divers documents canoniques ou juridiques faisant état de l'existence autocéphale de l'Église orthodoxe monténégrine. En 1851, l'Église monténégrine apparait dans le catalogue du Saint Synode des Églises russes ; en 1855, elle est mentionnée dans le syntagme d'Athènes du Patriarcat œcuménique de Constantinople ${ }^{16}$. Mais l'Église russe n'avait théoriquement pas le droit canonique de reconnaitre l'autocéphalie monténégrine ; en outre, les auteurs du syntagme (Ralis et Potlis) ont en réalité reconnu la Métropolie monténégrine dans le cadre de l'Église serbe en tant qu'exarchat ${ }^{17}$. Ces documents, tout comme l'histoire, font l'objet de diverses interprétations selon le positionnement pro-serbe ou pro-monténégrin des commentateurs. Pour les uns, ils témoignent de la reconnaissance canonique de l'autocéphalie monténégrine. Pour les autres, ils ne constituent que la reconnaissance de l'autonomie dans le cadre du Patriarcat de Peć, aboli. Toutefois, ces documents, remis en perspective, n'ont probablement pas la portée qu'on leur attribue. Lorsque Bartholomé, patriarche de Constantinople déclare à Pobjeda (quotidien monténégrin) qu'il n'a pas connaissance que l'Église monténégrine ait jamais été autocéphale, les " pro-Monténégrins " rétorquent que le formalisme canonique n'a pas lieu d'être au vu de l'histoire atypique du Monténégro. Selon eux, l'autocéphalie est toujours une revendication nationale, avant d'aboutir à une reconnaissance canonique. D'ailleurs, soulignentils, il n'existe pas une seule Église orthodoxe qui ait obtenu son indépendance par des voix canoniques ${ }^{18}$.

Toutefois, officiellement, l'autonomie d'une éparchie rattachée au Patriarcat de Peć est tolérée mais cette autonomie n'est pas une autocéphalie

13 Ibid., pp. 222-223.

14 Stamatovic (Aleksandar), Kratka istorija mitropolije crnogorsko-primorske, 1219-1999 (Brève histoire de la Métropolie du Monténégro et du Littoral), Beograd : Sveti Petar Cetinjski, 2000 (<http://www.mitropolija.cg.yu/istorijat/index_l.html〉).

15 Perović (Sreten). " Praznoj čaši molitve nema " (Ne pas prier le verre vide), Monitor, 20/03/98 : Radojevic (Danilo), art.cit., p. 226.

${ }^{16}$ Perović (Sreten), art.cit.

17 Stamatovic (Aleksandar), op.cit..

${ }^{18}$ Mlakar (Mirko), " Śćepan u odori " (Śćepan en tenue de gala), Monitor, o8/11/93. 
si elle n'est pas déclarée selon les canons ecclésiastiques. Historiquement, l'Église du Monténégro n'était rattachée à aucun Patriarcat, ce qui représente les racines de l'autocéphalie pour les " pro-Monténégrins ", tandis que pour les " proSerbes ", cela ne fait pas sens en soi.

Si l'autocéphalie, existante de facto, n'a jamais été reconnue de façon canonique, le courant " pro-monténégrin " en réfère pour sa part à la Constitution de la Principauté du Monténégro de 1905 qui mentionne dans son article 40 que " la religion de l'État est orthodoxe et l'Église monténégrine est autocéphale ${ }^{19}$. Néanmoins, la Constitution de 1905 ne mentionne pas auprès de qui elle a cherché son autocéphalie ni qui la lui a conférée. Par ailleurs, que l'autocéphalie soit mentionnée dans la Constitution du Prince Nikola indique qu'il s'agit d'une décision étatique et non ecclésiastique : si l'Église avait réellement été autocéphale, elle aurait obtenu cette autocéphalie de l'Église œcuménique et non d'un pouvoir séculaire.

Si les deux thèses s'opposent sur l'histoire avant la Yougoslavie, elles s'accordent sur l'union des Églises en 1920 qui met fin à l'Église monténégrine (exarchat pour les "pro-Serbes ", autocéphale pour les " pro-Monténégrins "). Lorsque, le 30 juin 1920, le Roi du Royaume des Serbes, Croates et Slovènes, Aleksandar Karadjordjević, proclame l'unité des circonscriptions orthodoxes, il décompte, parmi les Églises autocéphales qui s'unissent, le Patriarcat de Cetinje et la Métropolie des Montagnes et du Littoral du Monténégro ${ }^{20}$. De même la Constitution de l'Église serbe de 1931 évoque trois Églises orthodoxes serbes autonomes, indépendantes l'une de l'autre ${ }^{21}$; en revanche, le protocole 1036 du Patriarcat de Constantinople du 24 février 1922 considère que " dans les frontières de ce Royaume unifié des Serbes, Croates et Slovènes, sont entrées les Églises orthodoxes autocéphales de Karlovac et du Monténégro " ${ }^{22}$. Là encore, les interprétations divergent mais, de fait, l'unification de l'Église serbe en 1920 abolit les différences régionales qui pouvaient exister jusqu'alors ${ }^{23}$.

${ }^{19}$ Mitrić (Blagota), “Crnogorska crkva je bila autokefalna " (L'Église monténégrine était autocéphale), Monitor, 06/11/98 ; Perović (Sreten), art.cit. ; Koprivica (Veseljko), " Božja i narodna pravda " (Droit du peuple et droit divin), Monitor, 20/03/98.

20 "Službeni list ujedinjene SPC n (Journal officiel de l'unification de la SPC), Glasnik, 1 (1), 14/07/20 (cité dans Radojević (Danilo), art.cit., p. 225). Cette "restauration " du Patriarcat serbe aurait coûté au royaume des Serbes, Croates et Slovènes 1500000 de francs-or versés au Patriarcat de Constantinople (cf. Perović (Sreten), " Amfilohijeva fildžan Crna Gora " (Le mazagran monténégrin d'Amfilohije), Monitor, 10/o4/98).

${ }^{21}$ Radojević (Danilo), art.cit., p. 225.

${ }^{22}$ Radović (Veljko), “ Uspenje kiča na Rumiju ” (Ascension kitsch à Rumija), Vijesti, 23/07/05.

23 Sont réunies la Métropolie de Serbie (5 éparchies, diocèses), autocéphale ; la Métropolie de Karlovac (7 éparchies), autocéphale ; la Métropolie du Monténégro et du Littoral (3 éparchies), autocéphale ; l'Église serbe en Bosnie-Herzégovine (4 éparchies), passée en 1878 sous la juridiction du Patriarcat de Constantinople; la région ecclésiastique dalmate ( 2 éparchies), passée sous la juridiction de Constantinople ; la région ecclésiastique en Vieille Serbie et Macédoine (6 éparchies), rattachée en 1912 
Cette unification orthodoxe représente le seul point d'accord dans les deux versions de l'histoire. Tout le reste fait l'objet de polemiques et de zones d'ombre. À titre d'exemple, nous nous appuyons sur deux textes, la version " pro-serbe ", tirée de l'historien Aleksandar Stamatovic, et une version "promonténégrine ", issue de l'historien Zvezdan Folic ${ }^{24}$. La Métropolie du Monténégro et du Littoral est créée en 1921 et le premier métropolite du Monténégro dans le jeune Royaume est Gavrilo Dožić, nommé le 17 novembre 1920. Il était également membre de l'Assemblée nationale de Podgorica qui avait voté en 1918 le rattachement au Royaume de Serbie. Il officie à une époque où l'Église représente l'instrument étatique d'intégration nationale serbe et est, selon $\mathrm{Z}$. Folić, le " digne représentant de l'idéologie officielle du yougoslavisme intégral ». Joanikije Lipovac lui succède (1941-1945). Il est, pour A. Stamatović, " assassiné à la fin de la guerre par les communistes ". Sans en donner les raisons, il mentionne seulement qu la Métropolie du Monténégro et du Littoral, lors de la guerre, "luttait contre les Oustachis, les occupants et le mouvement révolutionnaire ", c'est-à-dire avec les Tchetniks. De son côté, Z. Folić nous précise qu'il excommuniait et dénonçait les croyants qui participaient au mouvement communiste. Arsenije Bradvorović, élu en juillet 1947 , est emprisonné en 1954 puis confiné au monastère Sainte Vavedenja à Belgrade jusqu'à sa mort en 1963 . À nouveau, A. Stamatović n'apporte aucune précision sur les causes de son emprisonnement. $Z$. Folić mentionne pour sa part, que son arrestation serait due à sa critique ouverte de la fédéralisation de l'État. Danilo Dajković succède à Arsenije Bradvorović en 1961. Pour Z. Folić, il " surveille et étend la serbité ". Enfin, en 1991, est nommé Risto Radović, dont le nom de baptême est Amfilohije. A. Stamatović précise les conditions dans lesquelles il prend la direction de la Métropolie : " 50 années de communisme ont laissé leurs marques, les églises sont à l'abandon, les prêtres peu nombreux et, surtout, toute une génération a été endoctrinée, sécularisée et dénationalisée ". Le travail antichrétien et antiserbe d'un demi-siècle de communisme s'est notamment traduit par le morcellement de la nation serbe dans " quatre nouveaux États " : la république socialiste yougoslave, la Bosnie-Herzégovine, la Croatie et la Macédoine ; et en " trois nouvelles nations : monténégrine, macédonienne et musulmane ". Cette nation a également été divisée religieusement : tout d'abord a èté créée l'Église orthodoxe macédonienne ; et aujourd'hui la mème chose se déroule pour le Monténégro. Selon lui, il faut impérativement rétablir l'orthodoxie serbe. En revanche, pour l'hebdomadaire

au Patriarcat de Constantinople). Cf. Rastoder (Serbo), "Istoriografija u Crnoj Gori 1989-2001 " (L'historiographie au Monténégro, 1989-2001), Centar za proučavanje historije, avril 2002 (dokument br. 99b-2002).

${ }^{24}$ Stamatovic (Aleksandar), op.cit.; Folic (Zvezdan), " Amfilohije je kontinuitet " (Amfilohije représente la continuité), Monitor, 16/09/05. 
"pro-monténégrin ", Monitor, Amfilohije Radović perpétue le travail de son prédécesseur, à savoir " absorber les orthodoxes du Monténégro dans le corpus ethnique serbe $n$.

\section{Deux Églises, deux idéologies}

L'Église serbe est obsédée par le destin tragique du peuple serbe dans l'histoire. Elle estime avoir contribué de façon décisive à la conscience nationale serbe en sauvegardant l'héritage médiéval de l'État serbe. S'affirmant comme le protecteur ultime de l'identité nationale serbe, elle considère la distinction entre Église et nation non-pertinente ${ }^{25}$. De fait, elle analyse l'unification des Slaves du sud en 1918 comme représentant également l'unification des Serbes $^{26}$. Elle s'oppose au morcellement de la serbité qu'ont pratiqué les communistes ${ }^{27}$ et développe un complexe victimaire ${ }^{28}$, parfois assimilé à du fondamentalisme orthodoxe $\mathrm{e}^{29}$, estimant que le peuple serbe dans son ensemble a souffert pour la foi du Christ bien plus que d'autres ${ }^{30}$.

Effectivement, le régime communiste encourage un séparatisme ecclèsiastique au Monténégro dans l'immédiat après-guerre ${ }^{31}$, dans le cadre de la politique d'encouragement national ${ }^{32}$. Le soutien cesse lorsque l'Église serbe accepte l'autonomie de l'Église orthodoxe macédonienne ${ }^{33}$. La décomposition

25 Van Dartel (Geert), "Nationalities and religion in Yugoslavia ", in van den Heuvel (Martin), Siccama (Jan G.), eds., The disintegration of Yugoslavia, Amsterdam / Atlanta : Rodopi, 1992, p. 37.

${ }^{26}$ Cf. Ramet (Pedro), "The Serbian Orthodox Church", in Ramet (Pedro), ed., Eastern Christianity and Politics in the Twentieth Century, Durham / London : Duke University Press, 1988, p. 234.

27 L'autocéphalie macédonienne, déclarèe en 1967, n'est toujours pas reconnue par l'Ėglise serbe. À l'époque, elle affirmait que " les Macédoniens sont un groupe ethnique et l'indépendance ecclésiastique des groupes ethniques est contraire aux intérêts de l'orthodoxie " (synode SPC, 14/09/67, cité in Banac (Ivo), " Universalist religions in a multinational society : Yugoslavia since 1966 ", Cross Curents, 7 (1), 1988, p. 68).

${ }^{28}$ Ce complexe victimaire est analysé par S. Ramet. Cf. Ramet (Sabrina Petra), " The Serbian church and the Serbian nation " in Ramet (Sabrina Petra), Adamovich (Ljubiša S.), eds, Beyond Yugoslavia : Politics, Politics, Economics, and Culture in a Shattered Communit, Boulder : Westview Press, 1995.

29 Cf. Gredelj (Stjepan), " Klerakilzam, etnofiletizam, anti-ekumenizam i (ne)tolerancija " (Cléricalisme, ethnophilie, anti-œucuménisme, et (in)tolérance), Sociologija, 41 (2), 1999.

30 Prêtre Lazar Milin, dans une brochure éditée au début des années 1970, cité in Ramet (Pedro), Cross and commissars. The politics of religion in Eastern Europe, Bloomington : Indiana university press, 1987, p. 15.

${ }^{31}$ Cf. Alexander (Stella), Church and State in Yugoslavia, since 1945, Cambridge / London / New York / Melbourne : Cambridge University Press [Soviet and East European Studies, (23)], 1979, p. 169.

${ }^{22}$ Cf. Michels (Patrick), " Les Monténégrins : création ou reconnaissance ? ", in Gervereau (Laurent), Tomic (Yves), éds., De l'unification à l'éclatement. L'espace yougoslave, un siècle d'histoire, Nanterre : Musée d'histoire contemporaine / BDIC, 1998, pp. 197-198.

33 Cf. Ramet (Pedro), art.cit., pp. 242-243. La reconnaissance de l'autonomie ne remet pas en cause la nonreconnaissance de l'autocéphalie. Elle permet, néanmoins, d'améliorer les relations entre l'Église orthodoxe serbe et l'État communiste, à tel point que ce dernier renonce à son soutien à l'Église autocéphale monténégrine. 
de la Yougoslavie ouvre la question de l'appartenance ecclésiastique des Monténégrins, associée à celle de l'appartenance nationale. L'Église serbe, affirme Amfilohije, souhaite les Serbes unis dans un seul Etat 34 . La nation monténégrine ayant été, selon lui, "créée dans le laboratoire de Tito et de Djilas "35, le Monténégro doit donc intégrer la Serbie comme il l'a fait en $1918^{36}$. La fin du communisme permet à l'Église orthodoxe de s'engager dans l'activité politique, de restaurer des cérémonies religieuses pré-communistes, et de développer des activités caritatives et éducatives ${ }^{37}$. Il lui est également ouvert le droit d'acquérir divers biens.

Au Monténégro, le métropolite du Monténégro et du Littoral soutient diverses réunions commémoratives du mouvement tchetnik. Amfilohije évoque alors les luttes contre le fascisme et le communisme, ravivant parfois l'animosité des populations pro-monténégrines ${ }^{38}$. Investissant le champ politique, Amfilohije n'hésite pas à afficher son anticommunisme, prônant la destruction du mausolée de Njegoš et la restauration de la chapelle sur le mont Lovćen. En janvier 2005, au monastère de Dajbade, Amfilohije soutient une réunion sur la protection de l'État commun, l'Église et la langue ${ }^{39}$. En plus de se consacrer à ses tâches religieuses, le métropolite Amfilohije parvient à revêtir le rôle d'un leader politique. Sa défense des Serbes est inconditionnelle. Il encense les deux Karadžić (Vuk et Radovan, jouant sur leur homonymie) et comparé Biljana Plavšić à la jeune fille du Kosovo, celle qui vient abreuver les héros agonisants sur le champ de bataille de $1389^{\circ}$. Les moyens à sa disposition sont sans commune mesure avec ceux dont dispose l'Église monténégrine. Depuis l'unification de l'Église orthodoxe serbe en 1920, les églises lui appartiennent ${ }^{41}$.

Le patriarche de l'Église monténégrine demande donc, pour sa part, à ce que les 650 lieux saints qui sont aux mains de l'Église serbe lui soient « rendus ». Sans église, il est difficile de baptiser, marier, célébrer une messe. Ainsi, l'Église orthodoxe monténégrine commence à préciser ses ambitions et formule ses re-

\section{$34 \mathrm{Nin}, 17 / 07 / 92$.}

35 Koprivica (Veseljko), "Zatri bliżnjega svoga " (Nuis à ton prochain), Monitor, 01/11/02.

$3^{6}$ En ce sens, il est soutenu par l'Acadèmie serbe des Sciences et des Arts (cf. Papović (Stanko), "Njegos̄ev naslednik " (L'héritier de Njegos̃), Vreme, 07/01/91; Stamatović (Aleksandar), Istorijske osnove nacionalnog identiteta crnogoraca 1918-1953 (Racines historiques de l'identité nationale des Monténégrins), Zemun : Srpska radikina stranka, 2000, p. 296).

37 Cf. Slater (Wendy), Engelbrekt (Kjell), " Eastern Orthodoxy defends its position ", RFE/RL Research Report, 2 (35), 03/og/95.

${ }^{38}$ Ce fut ainsi, par exemple, le cas à Lješanka en 1995, où les combats entre cousins et voisins ont abouti à l'intervention de la police et l'interdiction des liturgies, cf. Koprivica (Veseljko), art.cit.

39 Cf. "Populism and the church in Montenegro (part 2) ", South Slavic Service, 7 (26), 08/09/05.

$4^{\circ}$ Cf. Vojičić (Branko), " Amfilohije, bič boz̄ji " (Amfilohije, fléau de Dieu), Monitor, 29/o7/o5.

${ }^{41}$ Cerović (Rajko), “Otvaranje Pandorire kutije " (L'ouverture la boite de Pandore), Monitor, 22/o2/o2. 
vendications. Contrairement à l'Église serbe, le parti pris est ouvertement " promonténégrin ", avec un fervent soutien de l'indépendance du Monténégro et, conjointement, la reconnaissance des Monténégrins comme nation à part entière. Elle a bénéficié en temps de guerre du soutien des partis " pro-monténégrins " opposés à Milošević. Détachée du soutien guerrier dont a fait montre sa concurrente, elle acquiert une aura pacifiste. Face à son manque de moyens, et bénéficiant du nouveau contexte indépendantiste ${ }^{42}$, l'Église monténégrine commence à réagir. Elle envisage de construire une église en Voïvodine, dans le village de Lovćenac, majoritairement peuplé de Monténégrins installés dans la région depuis $1945^{43}$. Puisqu'elle est légalement enregistrée au niveau de l'Union de Serbie-et-Monténégro et malgré l'absence de reconnaissance canonique 44 , l'Église monténégrine a le droit d'acquérir des terrains et de construire des églises 45 . En outre, elle n'hésite pas à faire appel aux instances internationales, comme c'est le cas pour faire valoir son droit sur l'église Saint Georges à Mirac.

Les discours de Mihajlo sont de fait teintés de nationalisme monténégrin. Le nationalisme monténégrin se veut tolérant 46 , les intellectuels, les sciences ne sont pas mobilisées dans la négation de l'autre. Les travaux pro-monténégrins sont consacrés pour l'instant à l'affirmation de la nation monténégrine. Celle-ci n'étant pas posée, ses fondements peu assurés, la principale fonction des sciences sociales se concentre sur la différenciation d'avec les Serbes. Paradoxalement, l'Église monténégrine, qui bénéficie de cette image de tolé-

\begin{abstract}
$4^{2}$ La chute de Milošević aurait dû affaiblir le courant indépendantiste, pourtant c'est le contraire qui se produit. C'est en 2001 que Djukanović opte pour l'indépendance. Les raisons du soutien public pour l'indépendance accru après 2001 se trouvent dans la croyance qu'elle favorisera un développement économique plus rapide, une amélioration de la situation politique, une position internationale plus avantageuse, le renforcement du développement démocratique, une plus grande assistance internationale, une accession plus rapide à l'UE et une amélioration du tourisme. Cf. " Public opinion on the relations of Serbia and Montenegro " (Yugoslav survey, (1), mars 2001, cité in Huszka (Beáta), " The Dispute over Montenegrin Independence ", in Bieber (Florian), ed., Montenegro in Transition. Problems of Identity and Statehood, Baden-Baden: Nomos, 2003, p. 48. C'est surtout la situation économique (49\% des répondants), plus que le statut de l'État (23\%) qui prime dans les réponses données en avril 2001 (Centar za tranziciju, Governing the state, Montenegro's citizens' opinion and attitudes, 2002, cité in ibid., pp. 49-50).
\end{abstract}

43 Beta, " Crnogorska pravoslavna crkva gradiće crkvu u selu Lovćenac, u opštini Mali Iđoš " (L’Église orthodoxe va construire une église dans le village de Lovćenac, commune de Mali Iđoš ), 08/08/05. Il ne s'agit pas, selon Ljubomir Perović, président de l'association culturelle Krstaš, d'une réponse à la situation à Rumija, mais le fruit d'un projet de long terme (Beta, " Uticaj običajnog prava na gradnju ", 10/08/05).

44 Milan Radulović, ministre du Culte en Serbie, affirme que ces églises ne peuvent pas être enregistrées comme églises, car ne peut pas être enregistré ce qui n'existe pas. Beta, " Uticaj običajnog prava na gradnju ", 10/08/05.

45 Beta, "Crnogorska pravoslavna crkva gradiće crkvu " (art.cit.).

${ }^{6} 6$ Il est " sans prétention territoriale " (Filipović (Mileva), " Paradigma za konstrukciju nacionalnih identiteta " (Paradigmes pour la construction des identités nationales), Sociologija, 43 (4), 2001, p. 317), lié à la tolérance et la co-existence inter-ethnique (Bieber (Florian), "Montenegrin politics since the disintegration of Yugoslavia n, in Bieber (Florian), ed., op.cit., p. 42). 
rance, associée au camp pro-monténégrin, s'inscrit également dans une concurrence symbolique avec l'Église serbe et participe à un jeu de provocations réciproques figeant les deux parties. De facto, cette " guerre froide " entre les deux Églises paraît loin de prendre fin.

\section{CRISTALLISATION DU SCHISME RELIGIEUX SUR FOND DE PROVOCATIONS RECIPROQUES}

En 1993, la " restauration " ou la " création " de l'Église orthodoxe monténégrine sert de point d'appui à l'affirmation de l'identité monténégrine et à la dénonciation des crimes commis au nom de la " Grande Serbie "47. Fruit des activités du Comité pour la restauration de l'Église autocéphale ${ }^{4}{ }^{8}$, débutées en 1989 " contre la serbisation et l'abandon du Monténégro à la Serbie ", elle n'obtient pas de réelle reconnaissance des autorités, ni beaucoup de partisans 49 . Peu soutenue, l'Église monténégrine reste d'abord en retrait et évite toute provocation. Néanmoins, le gouvernement de Momir Bulatović, allié de Slobodan Milošević, tente de dissuader l'archevêque Antonije Abramović de prendre la charge de l'Église autocéphale monténégrine ${ }^{50}$. Celui-ci décède en 1996 et est remplacé par Miraš Dedeić, sous le nom ecclésiastique de Mihajlo, qui prend ses fonctions à Noël 1997 ( 6 janvier). Il se démarque de son prédécesseur en affirmant l'existence de l'Église autocéphale monténégrine qui doit être l'Église des Monténégrins ${ }^{51}$. Il se positionne tout de suite comme un opposant à Amfilohije. L'orientation autonomiste du Monténégro que prône le nouveau

47 Dérens (Jean-Arnault), " Orthodoxie : l'Église serbe face aux schismes macédonien et monténégrin ", Religioscope, 2004 (<http://religion.info/french/articles/article_64.shtml〉). Ce qui constituerait les raisons du soutien que lui accorde la Ligue libérale (qui a critiqué la participation du Monténégro à la guerre en Croatie, le nationalisme serbe et l'Église serbe) ; cf. Bieber (Florian), art.cit. Bien que la " restauration " de l'Église monténégrine permette également de renforcer l'identité nationale spécifique monténégrine.

$4^{8}$ Composé notamment de Jevrem Brković (écrivain), Milorad Popović (écrivain), Milo Pavlović (peintre), Dušan Gvozdenović. Ce comité qualifie la Métropolie du Monténégro et du Littoral (donc l'Église serbe) de " résidu de l'occupation serbe du Monténégro en 1918 " (Ramet (Sabrina Petra), art.cit., p. 116). La nomination d'Amfilohije fait accélérer le projet (cf. Jokić (Branko), "Plus Crnogorci" u nemilosti vlasti " (Les "Monténégrins plus" en état de disgrâce), Vreme, 11/03/91).

49 Bieber (Florian), art.cit., p. 26.

$5^{\circ}$ Il l'accuse d'être homosexuel et d'avoir été un agent des services secrets yougoslaves aux États-Unis (cf. Brajović (Velizar), "Opkoljavanje popa " (Encerclement du pope), Monitor, 22/11/93 ; Brajović (Velizar), " Borba za crkveno zvono " (Lutte pour la cloche de l'église), Monitor, 08/11/93).

${ }^{51}$ Notamment, il déclare dès sa prise de fonction que " l'Église orthodoxe monténégrine n'appartiendra à personne et le peuple monténégrin appartiendra à l'Église autocéphale monténégrine n (cité in Šuković (Darko), " Bjekstvo iz svjetovnih zamki " (Évitement des pièges de profane), Monitor, 10/01/97). 
président monténégrin Milo Djukanović, élu en 1997, coïncidant avec sa nomination l'incite peut-être à des prises de position plus virulentes.

Profitant du nouveau climat politique au Monténégro, Mihajlo est intronisé en mars 1998 par le patriarche Pimen de l'Église orthodoxe bulgare ${ }^{52}$, avec le soutien de l'une des Eglises autocéphales ukrainiennes. Cette intronisation implique la reconnaissance de l'autocéphalie monténégrine mais elle n'a pas fait l'objet de reportage télévisé53 marquant l'absence de soutien officiel. Le 31 octobre de la même année (1998), il est élevé au rang de métropolite à Cetinje en présence de l'evêque Evlohije et le métropolite Antonije du saint Synode bulgare. Le métropolite de l'Église orthodoxe serbe, Amfilohije, considère que " la soi-disant consécration du défroqué Miraš Dedeić (...) par des peudoévèques inconnus (...) représente un acte de pure violence politique ". Cette fois-ci, la télévision diffuse des reportages, mais consacrés à la réunion de la Métropolie du Monténégro et du Littoral ${ }^{54}$. Le gouvernement de Djukanović reste à l'époque indécis sur le sort à réserver à l'Église monténégrine : sans l'interdire, il ne la plébiscite pas.

Les associations de la diaspora monténégrine aux États-Unis sont réunies à San Francisco les 28 et 29 septembre 2002 en présence du métropolite Mihajlo et du Reis Idriz Demirović, le responsable de la communauté islamique du Monténégro. Cette réunion symbolise la tolérance religieuse et nationale de la Mère patrie au sein de la diaspora (les associations réunies prönent un Monténégro souverain, démocratique, multiethnique et multiconfessionnel). Elle indique surtout la tolérance qu'incarnerait l'Église monténégrine et précède de peu l'intronisation, en tant que patriarche, de Mihajlo55. Les 28 et 29 octobre 2002, les Églises orthodoxes monténégrine et russe se réunissent à Cetinje. Deux évêques orthodoxes russes rejoignent l'Église monténégrine. Désormais, celle-ci peut introniser de nouveaux évêques et former son propre synode ${ }^{56}$, ce qui est fait le 31 octobre. S'estimant alors sur un pied d'égalité, non plus avec la Métropolie, mais avec le Patriarcat serbe, Mihajlo déclare qu' ' il est temps que ceux qui sont entrés dans les saintes églises monténégrines et au Monténégro délaissent nos édifices sanctifiés et le Monténégro (...) de leur propre volonté et en sachant que leur place n'est plus parmi les Monténégrins "57.

${ }_{52}$ Il existe en Bulgarie une autre Ėglise orthodoxe, dont le patriarche Maksim n'est pas reconnu comure légitime, ayant été nommé par les communistes.

53 Koprivica (Veseljko), " Božja i narodna pravda " (art.cit.).

54 Koprivica (Veseljko), “ Vlast na nebu, narod na zemlji " (Pouvoir au ciel, peuple à terre), Monitor, $06 / 11 / 98$.

55 Cerović (Rajko), "Nova svijest i pokoja sjenka " (Nouvelle conscience et ombres diverses), Monitor, $11 / 10 / 02$.

${ }^{56}$ Cerović (Rajko), "Odlučni koraci " (Des pas assurés), Monitor, 01/11/02.

57 “ Osnovan sveti sinod " (Création du saint Synode), Monitor, 08/11/02. 
Ces événements participent activement à ce jeu de provocations réciproques que se livrent les deux Églises. De son côté, l'Église serbe n'est pas en reste.

Le 18 juin 2005, un hélicoptère de la $172^{\text {ème }}$ Brigade Aéroportée de l'Armée de Serbie-et-Monténégro de Podgorica dépose à 1593 m d'altitude, sur le mont Rumija, depuis Bar, deux blocs de métal, à la demande du Conseil ecclésiastique de Podgorica, dépendant de la Métropolie du Monténégro et du Littoral, diocèse de l'Église orthodoxe serbe. Ces deux blocs, assemblés, forment l'église orthodoxe de la Sainte Trinité. Ce dépôt met fin à une ancienne pratique religieuse partagée par plusieurs communautés $5^{8}$. Il indique en outre la collusion entre la Métropolie du Monténégro et du Littoral et l'armée. Il révèle à nouveau l'investissement du champ politique par son représentant, le métropolite Amfilohije. En effet, l'initiative a une signification politique, elle réaffirme la présence de l'Église serbe au Monténégro, niant la présence du même coup de l'Église monténégrine. Rumija constitue un épisode particulier de l'affirmation de la présence de l'Église orthodoxe serbe au Monténégro. Par la symbolique de l'église arrivee par les airs et sise sur les hauteurs, il affirme la primauté de l'orthodoxie sur les autres religions. En outre, cette installation est, pour l'Église serbe, un moyen de réaffirmer le caractère serbe du Monténégro.

Le culte pluriculturel détruit, l'orthodoxie affirmée, l'Église serbe en appelle à la tolérance. Le 24 juillet, le métropolite Amfilohije, dans un courrier adressé au Premier ministre monténégrin, Milo Djukanović, soutient qu'enlever l'église est un acte de pur vandalisme. Rumija est si proche de la frontière avec le Kosovo, la présence de l'église est un signe adressé « aux terroristes qui s'y trouvent "59. Le patriarche de l'Église orthodoxe serbe, Pavle, lui fait écho dans un courrier du 27 juillet qu'il adresse à Svetozar Marović (président de Serbie-et-Monténégro), lui demandant de " ne pas détruire l'église que les Turcs ont détruit en 1571 "60. A contrario, le journaliste et écrivain Andrej Nikolaidis se demande comment l'on pourrait détruire ce qui n'est pas construit : " est-ce qu'une église se transporte par hélicoptère ? Sans autel, sans icône, sans architecture, aucun croyant ne peut y entrer, ni allumer de bougie

\footnotetext{
$5^{8}$ Le tumulus que l'église a écrasé date de 3000 ans. La tradition qui y est attachée est déniée. Celle-ci via le culte de Saint Vladimir (saint patron de la ville de Bar) était célébrée par les trois communautés reli-

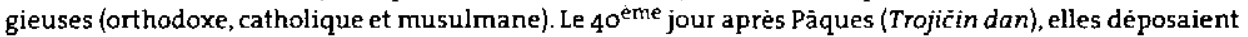
ensemble une croix et une pierre sur le tumulus (Cf. Vučinić (Stevo), " Razaranje tumula na Rumije je kulturocid " (La destruction du tumulus à Rumija est un culturocide), Vijesti, 30/07/05; Peric (Igor), "The Church in the Offensive: "The Miracle" of the Mt. Rumija ", Helsinki Charter, (85-86), july-august 2005 (<http://www.helsinki.org.yu/charter_text.php?lang=en\&idteksta=1491>).
}

59 "Amfilohije : rusenje neće proći mirno i bez posljedica " (Amfilohije : la destruction ne sera pas tranquille et sans consequence), Vijesti, 24/07/05.

6o "Pavle : ne dozvolite da zauvijek obraz nagrdimo" (Pavle : ne permettez pas qu'on perde l'honneur pour toujours). Vijesti, 28/07/05. 
(...). C'est une maquette ${ }^{61}$. Le dépôt de l'église à Rumija ne constitue pas la première appropriation symbolique de l'Église serbe. Il n'est qu'un élément dans une suite de contrôle ecclésiastique sur les biens religieux que l'État communiste a laissé à l'abandon. Ce n'est pas non plus la dernière.

Ainsi, à Beška, aux abords du lac de Skadar, cinq prêtres et une dizaine de croyants de l'Église monténégrine avaient commencé, début février 2005, à restaurer deux églises délaissées, Saint George et Sainte Bogorodica. Dès qu'elle en fut informée, la Métropolie du Monténégro et du Littoral a appelé les orthodoxes de Zečani, Crmničani et Beranci à défendre les lieux. La police s'interposa, conseillant à l'Église monténégrine de revenir quand les tensions seraient apaisées. Quelques jours plus tard, la police quittait les lieux, immédiatement occupés par les prêtres de la Métropolie. Mi-février, l'armée venait aux côtés de l'Église serbe pour conforter cette occupation. L'affaire portée devant les tribunaux semble aujourd'hui oubliée ${ }^{62}$. Fin août 2005 , la réplique de la chapelle de Njegoš, détruite par le gouvernement communiste en 1952 afin de dresser, à sa place, le mausolée de Njegoš, symbole national non religieux ${ }^{63}$, est achevée et sanctifiée sur le Mont Bjelašica par l'Église serbe ${ }^{64}$. Là encore, le gouvernement ne prend pas position.

\section{CONCLUSION}

Cette étude démontre les jeux auxquels se livrent deux Églises orthodoxes partageant le même territoire et revendiquant les mêmes fidèles. Elles ne luttent pas pour déterminer laquelle attire le plus d'ouailles mais, de façon plus large, se disputent la légitimité ecclésiastique sur l'espace géographique concerné. Pour les " pro-monténégrins ", depuis la moitié du XIX ${ }^{\text {ème }}$ siècle, la politique de l'Église serbe consiste à faire coïncider orthodoxie et serbité65. A contrario, pour les " pro-serbes ", l'Église monténégrine participe à un projet plus vaste de désintégration de l'héritage culturel serbe. La stratégie du gouvernement monténégrin de Djukanović a toujours été, face à ces deux Églises, de se détacher des polémiques. Loin des querelles identitaires, celui-ci semble

\footnotetext{
${ }^{61}$ Nikolaidis (Andrej), " Povratak mržnje u velikom stilu " (Retour de la haine de grand style), Monitor, 29/07/05.

${ }^{62}$ Cf. Nikolić (Predrag), " Udarnici u mantijama " (Les meilleurs ouvriers en soutane), Monitor, 28/o6/o2. Il a été fait appel du jugement qui sommait l'Église monténégrine de quitter les lieux. Les conclusions du tribunal étaient que les devoirs et obligations de l'archevêque Mihajlo n'étaient pas définis.

${ }^{6}$ Et construit par le sculpteur croate Ivan Meštrović.

64 Cf. Peric (Igor), art.cit.
}

65 Radojević (Danilo), art.cit. 
mettre en exergue les bienfaits économiques de l'indépendance. Si l'hebdomadaire Monitor estime qu'un Monténégro indépendant résoudra la question ecclésiastique en faveur de l'Église monténégrine ${ }^{66}$, cette affirmation mérite peut-être d'être nuancée. En effet, la dissociation établie par le pouvoir entre la question de la souveraineté et celle de l'héritage culturel monténégrin pourrait bien perpétuer les divisions et les polémiques identitaires, y compris dans un Monténégro indépendant. 